\title{
Model Penghindaran Tabrakan Multi Obyek Menggunakan Repulsive Field
}

\author{
Akuwan Saleh ${ }^{1}$, Moch. Hariadi ${ }^{2}$, Supeno Mardi S. ${ }^{2}$ \\ ${ }^{1,2}$ Pasca Sarjana, Jurusan Teknik Elektro, Fakultas Teknik Industri \\ Institut Teknologi Sepuluh Nopember, Surabaya \\ e-mail: akuwan@eepis-its.edu, mochar@ee.its.ac.id, mardi@ee.its.ac.id
}

\begin{abstract}
Abstrak
Mendeteksi tabrakan antar obyek dan menampilkan gerakan penghindaran tabrakan yang alami menjadi topik yang diinginkan dalam berbagai aplikasi navigasi agen otonom. Pada umumnya, gerakan penghindaran tabrakan multi obyek statis dan dinamis secara alami banyak menggunakan teknik dengan pengambilan keputusan untuk bergerak menghindar kearah lain. Teknik penghindaran ini mengalami kesulitan ketika jumlah obyek diperbanyak.

Pada penelitian ini menyajikan teknik yang maтpu menampilkan gerakan penghindaran tabrakan multi obyek statis dan dinamis secara alami. Metode yang digunakan Sphere-Plane Detection (SPD) dan Sphere-Sphere Detection (SSD) untuk mendeteksi tabrakan dengan referensi jarak dan metode potential field jenis repulsive untuk penghindaran tabrakan. Pengujian dilakukan dengan jumlah obyek 100 yang terdiri dari 34 agen A, 33 agen $B$ dan 33 agen $C$, multi penghalang dengan dan tanpa repulsive, penghalang statis dan dinamis, serta diuji dalam animasi boid.

Dari pengujian yang telah dilakukan diperoleh nilai vektor $|V|$ dari posisi awal sampai ke tujuan untuk agen $A_{2}$ sebesar 51.4522, agen $B_{1}$ bernilai 45.0853 dan agen $C_{4}$ sebesar 27.7237, setiap agen memiliki lebih dari satu jalur untuk menuju tujuan, didapatkan tiga model gerakan penghindaran dan tiga parameter yang mempengaruhi gerakan agen yaitu perubahan nilai repulsive, jarak antar penghalang dan penghalang dinamis.
\end{abstract}

Kata kunci: deteksi tabrakan, SPD, SSD, penghindaran tabrakan, repulsive field.

\section{Pendahuluan}

Deteksi tabrakan merupakan bagian penting dalam game 3D. Ini memastikan bahwa permainan dengan dasar fisika relatif lebih realistis, sehingga obyek tidak terpotong ketika melalui benda lainnya atau melayang ketika harus jatuh. Seberapa baik permainan dapat mendeteksi tabrakan merupakan bagian integral dari believability dalam menikmati sebuah permainan. Sebuah sistem pendeteksian tabrakan di implementasikan dengan buruk dapat menjadi kelemahan untuk sebuah produk, sedangkan implementasi yang sangat baik dapat menghasilkan hasil yang luar biasa.

Dua bagian utama dalam tabrakan adalah mendeteksi apakah telah terjadi tabrakan atau tidak. Dengan demikian, menanggapi tabrakan dan menemukan jika tabrakan telah terjadi adalah dasar dari masalah ini.

Pada penelitian ini obyek yang berada dalam dunia virtual yang dibuat dengan VRML (Virtual Reality Modeling Language) adalah standar internasional untuk menggambarkan bentuk 3-D dengan pemandangan di World Wide Web [4]. Dilengkapi dengan sensor, salah satunya adalah bentuk sphere dengan radius tertentu, sehingga dapat menginformasikan apakah obyek lain berada dalam jarak jangkau sensor atau tidak, jika jaraknya sama dengan jangkauan sensor maka obyek akan menghindari tabrakan dengan bergerak ke arah lain.

Dengan menyatukan obyek-obyek statis maupun dinamis dalam satu scene pada dunia virtual dan memberikan metoda potantial field dengan jenis field repulsive dapat menghasilkan penghindaran terjadinya tabrakan antar obyek tersebut. Penerapan metode representasi berbagai shape dalam pemodelan 3D untuk animasi komputer, perlu adanya algoritma deteksi tabrakan yang dapat diterapkan pada koleksi benda yang terdiri dari beragam jenis shape [1]. Metode SpherePlane Detection (SPD), Sphere-Sphere Detection (SSD) dan deteksi penghindaran tabrakan antar obyek yang mengacu pada metode Potential Field khususnya jenis Repulsive sebagai algoritma yang ada pada penelitian ini yang akan disimulasikan. Penggunaan metode ini mampu menampilkan gerakan sebagai prepartikel dengan meminimalkan energi, dan mengadopsi rangkaian prespektif pada sistem. Hasil dari penilitian 
ini dapat diimplementasikan dalam animasi komputer tentang boid atau perilaku sekelompok agen.

\section{Kajian Pustaka}

\subsection{Metode Sphere-Plane Detection}

Salah satu cara untuk mendeteksi tabrakan dalam dunia virtual 3D adalah dengan menggunakan metode Sphere-Plane Detection (SPD) [5]. Pada gambar 1. merupakan metode SPD untuk menentukan apakah sebuah obyek memiliki berpotongan dengan bola. Jika jarak dari pusat bola ke sebuah obyek (d) kurang dari atau sama dengan jari-jari bola (r), maka tabrakan telah terjadi. Jarak antara titik, yang merupakan titik pusat bola dan plane dihitung dengan mengambil dot product posisi normal dan lingkup plane itu.

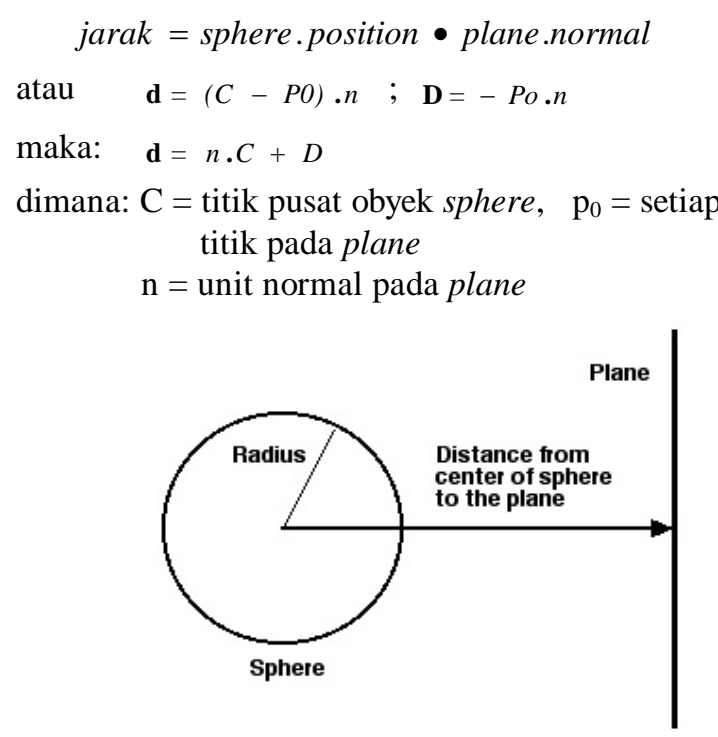

Gambar 1. Metode sphere-plane detection

Persamaan plane dengan dengan vektor normal $\mathrm{N}=(\mathrm{A}, \mathrm{B}, \mathrm{C})$ melalui titik $(\mathrm{x}, \mathrm{y}, \mathrm{z})$. adalah $A\left(x-x_{0}\right)+B(y-$ $\left.y_{0}\right)+C\left(z-z_{0}\right)=0$ atau $A x+B y+C z+D=0$, maka nilai $D=-A x_{0}-B y_{0}-C z$. Dengan demikian besar dari unit normal vektor dengan notasi $\mathrm{n}$ adalah:

$$
\mathbf{n}=\frac{N}{\|N\|}=\frac{(A, B, C)}{\sqrt{A^{\mathbf{2}}+B^{2}+C^{\mathbf{2}}}}
$$

\subsection{Metode Sphere-Sphere Detection}

Cara lain untuk mendeteksi terjadinya tabrakan antar obyek dengan sphere-sphere detection yaitu jika jarak dari pusat bola ke sebuah pusat obyek bola yang lain adalah kurang dari jumlah jari-jari kedua bola tersebut [2]. Sebagai ilustrasi diperlihatkan pada gambar 2 .

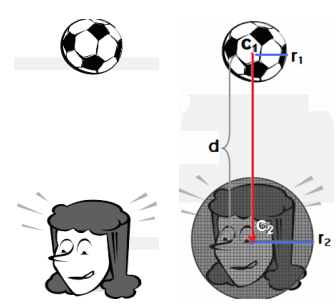

Gambar 2. Metode sphere-sphere detection

Persamaan untuk menentukan jarak antara obyek di atas adalah:

$$
\begin{aligned}
& \mathbf{D}=(C 2-C 1) \\
& \mathbf{d}=\sqrt{(D . x)^{2}+(D . y)^{2}+(D . z)^{2}}
\end{aligned}
$$

maka tabrakan telah terjadi jika:

$$
\mathrm{d}<(\mathrm{r} 1+\mathrm{r} 2)
$$

\subsection{Potential Field}

Penggunaan metode ini mampu menampilkan gerakan sebagai prepartikel dengan meminimalkan energi, dan mengadopsi rangkaian prespektif pada sistem. Memandu semua gerakan individu secara serempak. Menyatukan perencanaan alur global dan penghidaran benturan lokal ke dalam kerangka optimasi tunggal [8].

Ada dua model dari potensial field yaitu attractive dan repulsive [3]. Implementasi atraksi dan penghindaran dari kedua model potensial field ini adalah:

1. Tujuan: menggunakan model attractive field.

2. Rintangan: menggunakan model repulsive fields.

3. Agen: menggunakan model repulsive fields.

4. Hasil ideal: bergerak menuju sasaran sambil menghindari tabrakan dengan rintangan.

5. Rintangan dinamis: update potential field dengan bergerak cepat untuk menghindari rintangan.

Sebagai contoh diperlihatkan hasil trajektori robot.

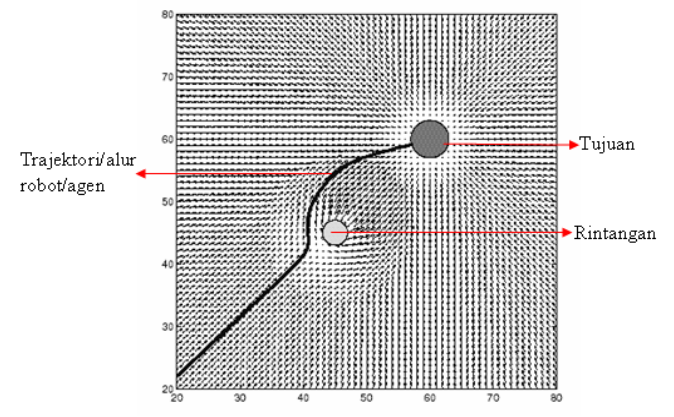

Gambar 3. Hasil trajektori $\operatorname{robot}^{[3]}$ 
Aplikasinya untuk perhitungan alur optimal dengan ketentuan penambahan dua medan divisualisasikan sebagai medan vektor:

$$
(x, y) \rightarrow(\Delta x, \Delta y)
$$

\subsection{Algoritma Boids}

Boids adalah sebuah algoritma yang merepresentasikan gerak dari sebuah kawanan. Perilaku yang dihasilkan sangat mirip dengan kumpulan ikan atau kawanan burung. Gerak boids dihasilkan dari tiga aturan sederhana yaitu cohesion, alignment, separation[7].

\section{Separation}

Pembatasan jika sebuah agen terlalu dekat dengan agen lainnya, dengan cara melakukan penyesuaian arah dan kecepatan untuk menghindari benturan (collision).

$$
\sum_{n \in N} \text { Normalize }\left(\text { agent }_{p o s}-n_{p o s}\right)
$$

\section{Alignment}

Mengambil rata-rata dari semua percepatan agen yang lain dan melakukan penyesuaian percepatan untuk pindah kearah kelompok

$$
\sum_{n \in N} \text { Normalize }\left(n_{v e l}\right)
$$

2)

\section{Cohesion}

Menghitung pusat keseluruhan kelompok dan mengarahkan agen ke arah titik pusatnya.

$$
\frac{\sum_{n \in N} n_{p o s}}{|N|}
$$

dimana:

$$
\begin{array}{ll}
\mathrm{n}_{\mathrm{pos}} & =\text { Posisi Jumlah Agen } \\
\text { agent }_{\mathrm{pos}} & =\text { Posisi Agen } \\
\mathrm{n}_{\mathrm{vel}} & =\text { Kecepatan Seluruh Jumlah Agen }
\end{array}
$$

\section{Disain Sistem}

\subsection{Desain Deteksi Tabrakan}

Desain obyek-obyek yang telah dibuat diantaranya yaitu obyek geometry box dan geometry sphere yang akan diterapkan sebagai metode SPD.

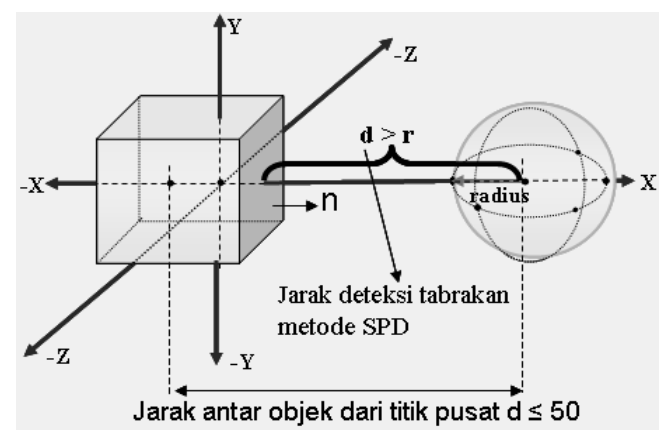

Gambar 4. Geometri box dan sphere

Algoritma dari metode SPD ditunjukkan pada gambar 5.

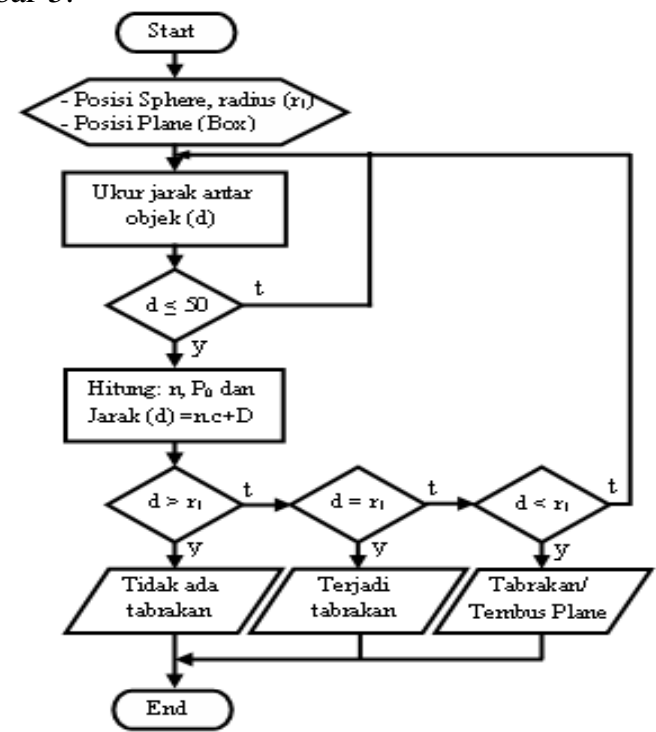

Gambar 5. Flowchart metode SPD

Obyek geometry sphere sebagai sensor pada mulut ikan dan geometry sphere sebagai makanan/bola merupakan penerapan metode SSD.

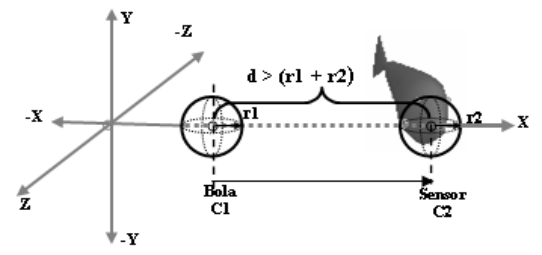

Gambar 6. Geometri sphere dan sensor sphere

Algoritma dari metode SSD ditunjukkan pada gambar berikut: 


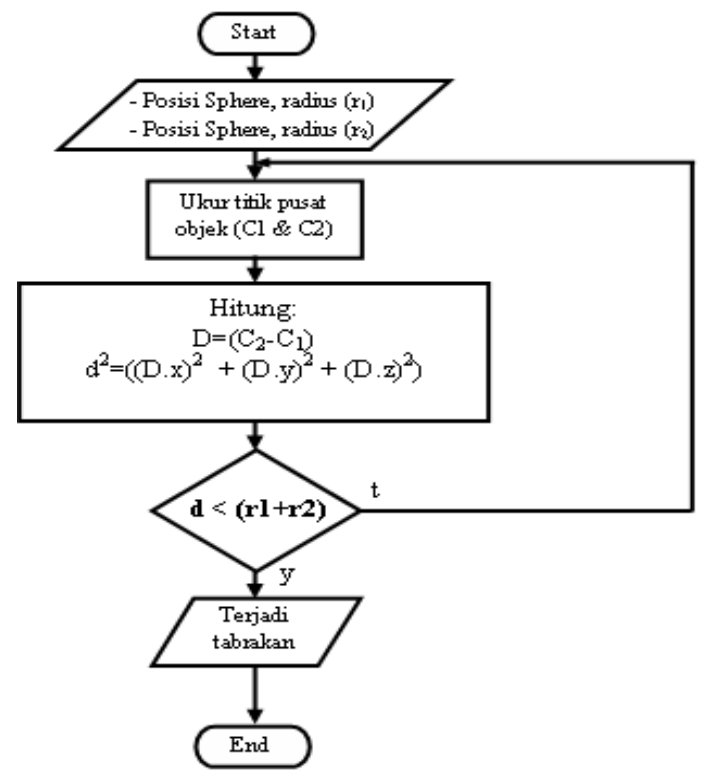

Gambar 7. Flowchart metode SSD

\subsection{Desain Penghindaran Tabrakan Antar Obyek}

Proses penghindaran tabrakan antar obyek didisain menggunakan metode repulsion/tolakan. Penggunaan metode potensial field jenis repulsive pada obstacle berbentuk bola dengan single dan multi agen diperlihatkan pada gambar 8 .

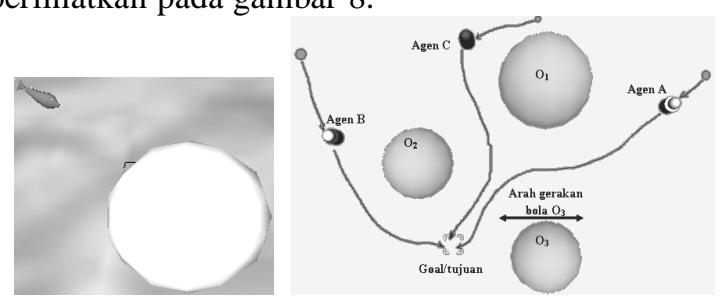

Gambar 8. Penggunaan repulsive field

3.3. Desain Penghindaran Tabrakan Antar Obyek pada Aplikasi Boids

\subsubsection{Algoritma Boid}

Penghindaran tabrakan antar agen dalam kelompok, penyesuaian kecepatan untuk pindah kearah kelompok dan mengarahkan agen ke titik pusat kelompok diilustrasikan seperti pada gambar 9 .

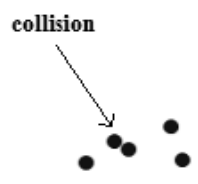

(a) Separation

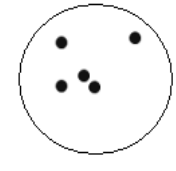

(b) Alignment

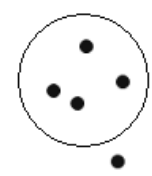

(c) Cohesion
Gambar 9. Ilustrasi boid

\subsubsection{Repulsive Field}

Penggunaan repulsive field pada aplikasi boid, diterapkan pada tiap agen dan obstacle. Pemberian repulsive pada agen bertujuan untuk melihat respon tolakan ketika terjadi collision baik antar agen maupun dengan penghalang.

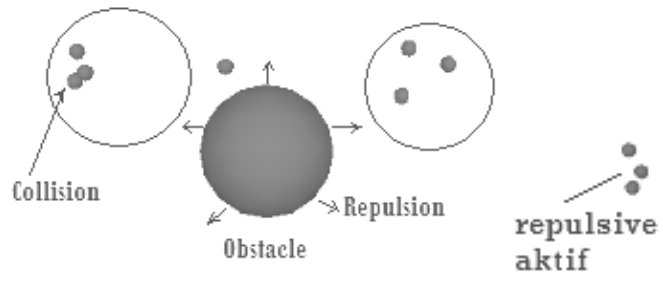

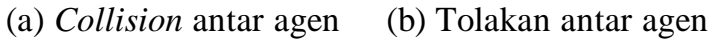

Gambar 10. Boid dan obstacle

\section{Analisa}

Pada bagian ini akan dilakukan pengujian berupa simulasi dan analisa dari metode $S P D, S S D$, Repulsive Field dan animasi boid.

\subsection{Pengujian Metode SPD}

Simulasi tabrakan kotak Vs Bola sebagai pengujian metode Sphere-Plane Detection.

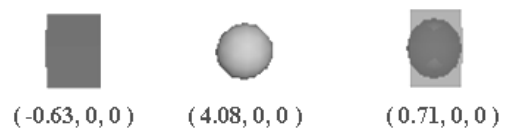

Posisi kotak untuk sumbu $\mathrm{x}, \mathrm{y}$, dan $\mathrm{z}$ adalah $(-0.63$, 0,0 ) dan posisi bola pada sumbu $\mathrm{x}, \mathrm{y}$, dan z yaitu (4.08, $0,0)$. Radius bola $=$ geometry Sphere $\{$ radius .8$\}$, Ukuran kotak = geometry Box $\{$ size 1.51 .51 .5$\}$, titik $\mathbf{p}_{0}$ $=(-0.63+(1.5 / 2)=0.12, \quad \mathrm{~N}=(0.12,0,0)$.

Persamaan plane : $A x+B y+C z+D=0$

$$
0.12+\mathrm{D}=0 \text {, maka } \mathrm{D}=-0.12 \text {. }
$$

Unit vektor $\mathrm{n}$ adalah (persamaan 3):

$$
\mathrm{n}=\frac{N}{\|N\|}=\frac{(A, B, C)}{\sqrt{A^{2}+B^{2}+C^{2}}}=\frac{(0.12)}{\sqrt{(0.12)^{2}}}=1
$$

Jarak (persamaan 2) $\mathrm{d}=4.08-0.12=3.96$ atau $\mathbf{d}>\mathbf{r}$. Dengan cara yang sama jarak kotak dengan bola ketika pada satu posisi $(0.71,0, \quad 0)$ adalah $\mathrm{d}=0.71-1.46=-0.75$ atau $\mathbf{d}<-\mathbf{r}$.

\subsection{Pengujian Metode SSD}

Simulasi tabrakan ikan Vs makanan/bola sebagai pengujian metode SSD. Bola dengan $\mathbf{r} 1=$ geometry Sphere $\{$ radius .1 $\}$ berada pada sumbu $\mathrm{X}, \mathrm{Y}$, dan $\mathrm{Z}$ adalah $(2.41,0,0)$, posisi ikan sumbu $\mathrm{X}, \mathrm{Y}$, dan $\mathrm{Z}$ 
yaitu ( 7.59, 1.4, -14.64), dan posisi sensor dengan radius $\mathbf{r 2}=$ bSphereRadius .5 berada pada koordinat (3.29, 0, 0). Hasil simulasinya sebagai berikut:

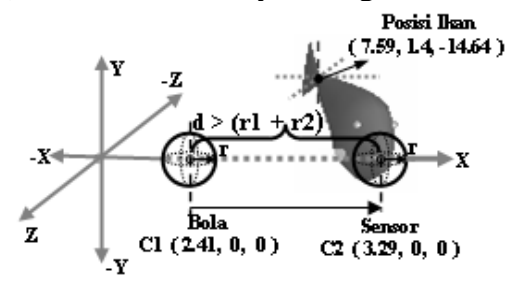

Perhitungan jarak (d) dari kedua obyek:

$$
\begin{aligned}
& \mathrm{d}=\sqrt{(D \cdot x)^{2}+(D \cdot y)^{2}+(D . z)^{2}} ; \mathrm{D}=(C 2-C 1) \\
& \mathbf{D}=(3.29-2.41)=0.88 ; \mathrm{r} 1+\mathrm{r} 2=0.1+0.5=0.6
\end{aligned}
$$

Sehingga nilai $\mathrm{d}$ adalah:

$$
\mathrm{d}=\sqrt{(0.88 \times 3.29)^{2}}=2.8952 \gg \mathbf{d}>(\mathbf{r} \mathbf{1}+\mathbf{r} \mathbf{2}) \text {. }
$$

Ketika posisi makanan satu posisi dengan sensor:

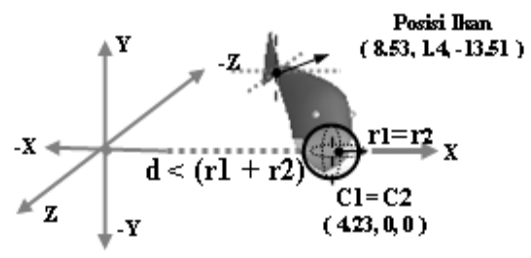

Jarak $\mathrm{d}=\sqrt{(0 \times 4.23)^{2}}=0 \gg \mathbf{d}<(\mathbf{r} \mathbf{1}+\mathbf{r} \mathbf{2})$.

\subsection{Pengujian Metode Repulsive Field}

Pengujian akan dilakukan dengan agen tunggal maupun multi agen.

\subsubsection{Penghindaran tabrakan agen dan penghalang tunggal}

Simulasi hambatan dinamis bentuk bola dengan nilai repulsion 500 bergerak kearah sumbu $+\mathrm{x}$ dan $-\mathrm{x}$ sedangkan sumbu y dan $\mathrm{z}$ konstan. Obyek hambatan mengakibatkan ikan bergerak menghindari tabrakan dengan model seperti pada gambar 11 .

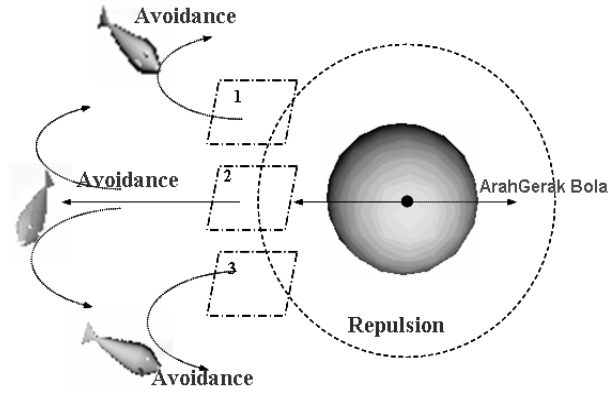

Gambar 11. Model gerakan avoidance
Tabel 1. Posisi terjadinya gerakan avoidance

\begin{tabular}{|c|c|c|c|c|c|c|}
\hline \multirow{2}{*}{ No } & \multicolumn{3}{|c|}{ Posisi Hambatan } & \multicolumn{3}{|c|}{ Posisi Ikan/Goal } \\
\cline { 2 - 7 } & $\mathbf{X}$ & $\mathbf{Z}$ & $\mathbf{Z}$ & $\mathbf{X}$ & $\mathbf{Y}$ & $\mathbf{Z}$ \\
\hline 1 & -3.14 & 0 & 7 & -5.28 & 0 & 4.07 \\
\hline 2 & -2.15 & 0 & 7 & -5.28 & 0 & 7 \\
\hline 3 & -2.84 & 0 & 7 & -5.28 & 0 & 9.98 \\
\hline
\end{tabular}

Pada posisi 1 ikan bergerak menghindar berputar menjauh menuju ke arah sumbu $-\mathrm{z}$, hal ini disebabkan oleh $Z_{\text {goal } \& \text { ikan }}<Z_{\text {hambatan, sehingga repulsion/tolakan }}$ dari hambatan mendorong ke arah -z. Pada posisi 2 ikan bergerak menghindar menuju kearah sumbu $-\mathrm{x}$ karena nilai $Z_{\text {goal } \& \text { ikan }}=Z_{\text {hambatan, }}$ sehingga repulsion dari hambatan mendorong ke arah sumbu $-\mathrm{x}$ kemudian ke arah $-\mathrm{z}$ atau z. Pada posisi ke 3 ikan bergerak menghindar berputar ke arah sumbu $+z$, karena nilai $Z_{\text {goal \& ikan }}>Z_{\text {hambatan, }}$ sehingga repulsion dari hambatan mendorong ke arah sumbu z positip.

\subsubsection{Penghindaran tabrakan multi obyek}

Jumlah agen $100($ agen $A=34$, Agen $B=33$ dan agen $\mathrm{C}=33$ ).

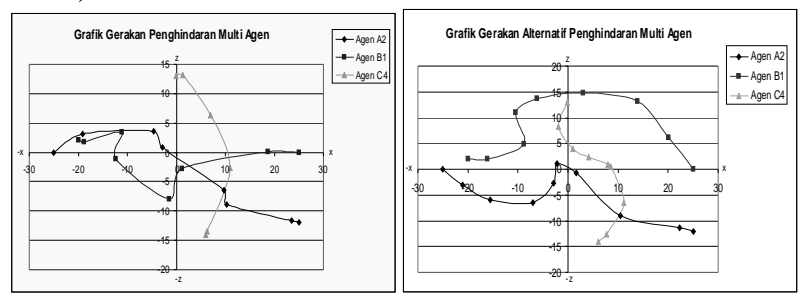

Gambar 12. Model gerakan avoidance multi agen

Vector dari $\mathrm{P} 1(25,0,-12)$ ke $\mathrm{P} 2=(23.45,0,-11.66)$ :

$$
\begin{aligned}
& |V|=\sqrt{(V x)^{2}+(V y)^{2}+(V z)^{2}} \\
& |V|=\sqrt{2.4025+0.1156}=1.58685
\end{aligned}
$$

Vector dari posisi awal $\mathrm{Pa}(25,0,-12)$ ke posisi akhir $\mathrm{Pb}$ $(-25.05,0,-0.07):|V|=\sqrt{2505.0025+142.3249}=51.4522$

\subsubsection{Perbandingan penggunaan repulsive dan non repulsive}

Jumlah Agen $=100$, jumlah obstacle (disable \& enable) repulsive field $=4$ (3 Obyek Bola \& 1 Obyek kotak). 


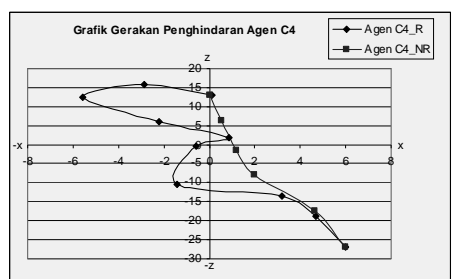

Gambar 13. Model gerakan avoidance menggunakan repulsive \& non repulsive

Pada simulasi Non Repulsive agen (C4_NR) bergerak menuju tujuan mengabaikan obstacle tanpa repulsive dan cenderung bergerak linier/lurus sebagai jalur terdekat untuk mencapai tujuan. Sedangkan pada simulasi repusive agen (C4_R) bergerak menuju tujuan menghindari obstacle dengan repulsive dan cenderung bergerak non linier.

\subsubsection{Pengaruh Perubahan Nilai Repulsive Field dan Jarak Antar Obstacle Terhadap Gerakan Agen}

Perubahan nilai repulsive field dan posisi dari obstacle mengakibatkan gerakan agen berubah seperti diperlihatkan pada gambar 14 .

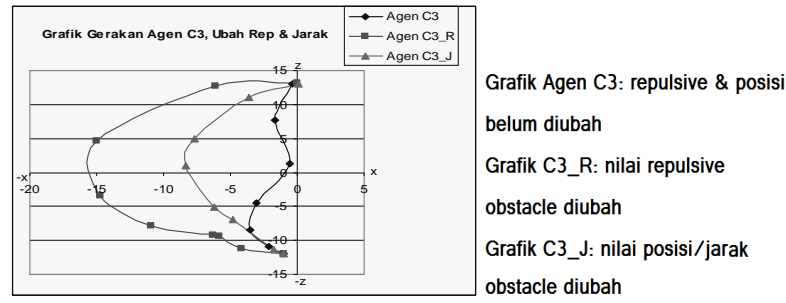

Gambar 14. Model gerakan avoidance hasil perubahan nilai repulsive field dan posisi obstacle

Grafik gerakan agen (C3_R) dari hasil perubahan nilai repulsive yang semakin besar mengakibatkan agen tidak dapat melewati cela diantara 2 obstacle karena repulsive field dari kedua obstacle tersebut berhimpit, sehingga jalur yang dilewati oleh agen untuk menuju tujuan semakin jauh. Grafik gerakan agen (C3_J) lebih pendek dari pada jalur (C3_R), ini disebabkan oleh semakin dekatnya jarak dari kedua obstacle sehingga repulsive field dari ke dua obstacle berhimpit.

\subsection{Pengujian Penghindaran Tabrakan Antar Obyek pada Aplikasi Boids}

Diketahui posisi setiap agen $\left(\right.$ agen $\left._{\text {Pos }}\right)$ dan kecepatannya, nilai $\mathrm{n}_{\mathrm{Vel}}$ adalah 33.5 dan $\mathrm{n}_{\text {Pos }}=2,0,-76$. Nilai repulsive field yang diberikan pada agen $=1$ dan obstacle $=175$, gambar 15 merupakan grafik gerakan menghindari benturan antar agen maupun dengan penghalang.
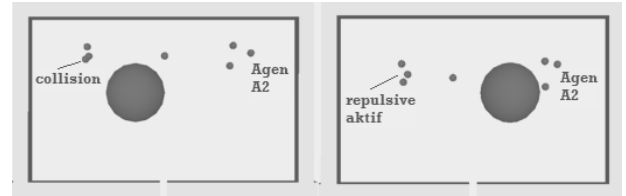

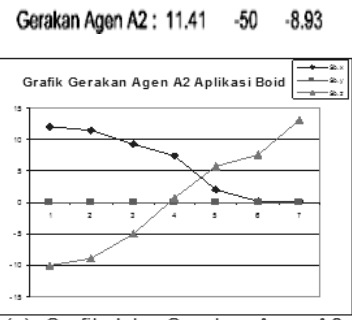

(a). Grafik Jalur Gerakan Agen A2 Aplikasi Boid pada Tiap Sumbu Koordinat
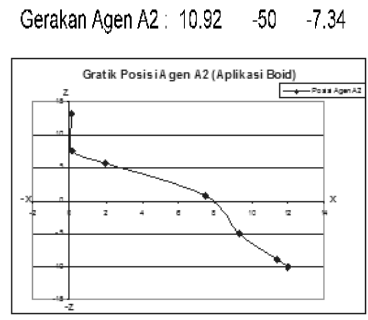
Aplikasi Boid (b). Grafik Posisi Agen A2 Pada

Gambar 15. Gerakan avoidance pada aplikasi boid

Pada gambar 15, ketika terjadi collision antar agen repulsive field langsung berfungsi menolak sehingga kedua agen tersebut terpisah kembali dan tidak terjadi tumpukan dari 2 agen pada 1 posisi.

\section{Kesimpulan}

Dari hasil simulasi dan analisa data di atas dapat ditarik kesimpulan bahwa :

1. Besarnya nilai vektor $|\mathrm{V}|$ dari posisi awal sampai ke tujuan untuk agen $\mathrm{A} 2=51.4522$, agen $\mathrm{B} 1=45.0853$ dan agen $\mathrm{C} 4=27.7237$

2. Tiga parameter yang mempengaruhi gerakan agen yaitu nilai repulsive, jarak dan gerakan penghalang.

3. Setiap agen memiliki lebih dari satu model jalur untuk menuju tujuan.

4. Tanpa repusive field pada penghalang grafik gerakan agen cenderung mendekati linier sebagai jalur terdekat mencapai tujuan.

5. Pemberian repulsive field pada agen maupun obstacle, pengaturan posisi dan kecepatan agen menghasilkan tiga aturan perilaku boid collision (separation), alignment dan cohesion (centering).

\section{Daftar Pustaka}

[1] Bergen Gino van den, (1999): "Collision Detection in Interactive 3D Computer Animation", Eindhoven University of Technology, University Press Facilities - Eindhoven.

[2] Gomes Miguel, (1999): "Simple Intersection Test For Games", at http://www.gamasutra.com/view/feature/3383/simple _intersection_tests_for_games.php 
[3] Kuipers Benjamin, (2009): Lecture 7: "Potential Fields and Model Predictive Control", CS 344R: Robotics.

[4] Nadeau David R, Moreland John L.\& Heck Michael M, (1998): "Introduction to VRML 97 - Lecturers", University of California at San Diego.

[5] PIGE, (2001): "Collision Detection", at http://www.edenwaith.com/products/ pige/tutorials/collision.php.

[6] Parallel Graphics, (2011): "Object-To-Object Collision Detection Interface", at http://www.parallelgraphics.com/developer/products /cortona/extensions/collision/

[7] Reynolds Craig W, (1987): "Steering Behaviors For Autonomous Characters", Sony Computer Entertainment America, Boulevard, California

[8] Treuille Adrien, Cooper Seth, Popovic Zoran, (2007): "Continuum Crowds", University of Washington, Electronic Arts.

[9] Tu Xiaoyuan \& Terzopoulos Demetri, (1994): "Artificial Fishes: Phisics, Locomotion, Perception, Behavior", Proc. ACM SIGGRAPH Conference. 